\title{
Surgical Management of Giant Pituitary Adenomas
}

\author{
Gérard Mohr, Jules Hardy, Ronald Comtois and Hughes Beauregard
}

\begin{abstract}
During the past 25 years, 77 giant pituitary adenomas have been treated surgically, including suprasellar extensions of type $C$ in 66 cases and of type D in 11 cases. Non-secreting adenomas were present in 53 and secreting adenomas in 24 cases. All patients except 3 presented with significant visual field defects; including bitemporal hemianopia, superior quadranopia or unilateral temporal hemianopia, contralateral blindness in $73 \%$ of the cases, and one case with sudden bilateral blindness due to acute pituitary apoplexy. A single transsphenoidal procedure was carried out in $74 \%$ of the patients while 11 patients $(7 \%)$ required re-operations for recurrent or residual tumor. Only 3 patients required a subsequent transcranial procedure. Complications included I CSF-leak, 1 empty-sella syndrome and 4 fatal post-operative hematomas. We prefer the transsphenoidal route even in very large or giant pituitary adenomas, since it allows rapid and adequate decompression of the optic nerves and chiasm, avoids major pituitary insufficiency in $60 \%$ of the cases and is associated with low morbidity-mortality rates.
\end{abstract}

RÉSUMÉ: Traitement chirurgical des adénomes pituitaires géants Au cours des 25 dernières années, 77 tumeurs hypophysaires géantes ont été traitées chirurgicalement, incluant 66 cas d'extensions suprasellaires de type C et 11 cas de type D. Il s'agissait d'adénomes non-sécrétants dans 53 et d'adénomes sécrétants dans 24 cas. Presque tous les malades sauf 3 présentaient des altérations importantes des champs visuels, dont des hémianopsies ou quadranopsies bitemporales, des hémianopsies unilatérales avec cécité contralatérale dans $73 \%$ des cas et un patient avec cécité bilatérale brutale par apoplexie pituitaire aiguë. Une seule intervention transsphénoïdale a été effectuée chez $74 \%$ des malades, tandis que 11 (7\%) subirent des réinterventions pour tumeur résiduelle ou récidivante. Seulement 3 malades nécessitèrent ultérieurement une chirurgie par voie transcrânienne. Parmi les complications, on observa 1 cas de fistule de LCR, l cas de selle vide et 4 hématomes postopératoires fatals. La voie transsphénoïdale est l'abord de choix même en cas d'adénomes très volumineux ou géants, permettant une décompression rapide et efficace des structures optiques, tout en évitant une insuffisance hypophysaire majeure dans $60 \%$ des cas et en assurant des taux de morbidité-léthalité très réduits.

Can. J. Neurol Sci. 1990; 17:62-66

Since Jefferson's description of unusually large suprasellar extensions of pituitary adenomas almost fifty years ago, 1,2 these giant lesions remain a significant challenge for neurosurgeons. ${ }^{3,4}$ In spite of the development of transsphenoidal microsurgical techniques, ${ }^{5}$ some authors still consider the subfrontal transcranial approach preferable for very large tumors. ${ }^{6}$

The introduction of dopamine agonistic agents (bromocriptine) has opened new perspectives in the management of prolactinomas since significant tumor shrinkage and reduction of serum-prolactin levels can be obtained thus preparing the patient's tissues for an easier surgical procedure. 7,8

Although the term macroadenoma of the pituitary seems to be generally accepted as defining a tumor measuring $2 \mathrm{~cm}$ of more in at least one diameter, 9.7 some ambiguity remains as to the definition of giant, ${ }^{4}$ massive, very large and huge ${ }^{10}$ adenomas. According to Symon et $\mathrm{al}^{3}$ giant adenomas should have an extension of more than $40 \mathrm{~mm}$ from the midline of the jugum sphenoidale in any direction or within $6 \mathrm{~mm}$ of the foramina of Monro. On the other hand, the classification used by Guiot and coworkers 11,12 implies that the largest suprasellar extensions (grade 3) reach or exceed the foramen of Monro, which is usually located $30 \mathrm{~mm}$ above the tuberculum sellae.

Our initial classification of pituitary tumors ${ }^{13}$ has recently been revised in the light of the newer imaging techniques, CTScanning and more particularly MRI-Scanning. Accordingly, microadenomas are now classified as intrasellar tumors of less

Table 1: Distribution of 77 Giant Pituitary Adenomas According to Pathology, Age and Sex (treated from 1962 through 1987 at NotreDame Hospital)

NON-SECRETING ADENOMAS $53 / 168$
Males: 29 (mean age 47.8 years)
Females: 24 (mean age 53.8 years)
SECRETING ADENOMAS $24 / 632$
Males: 16 (mean age 40.3 years)
Females: 8 (mean age 28.2 years)

PRL: 13, HGH: 7, ACTH: 1, LH-FSH: 2, TSH: 1

TOTAL $77 / 800$ $(9.6 \%)$ 
than $10 \mathrm{~mm}$ in diameter, macroadenomas with suprasellar extensions (SSE) include grade A (moderate SSE within $10 \mathrm{~mm}$ above the jugum sphenoidale, filling the chiasmatic cistern), grade B (large SSE, up to $20 \mathrm{~mm}$, elevating the anterior recess of the third ventricle), grade C (very large SE, up to $30 \mathrm{~mm}$, filling the anterior third ventricle) and grade D (huge SSE, in excess of $30 \mathrm{~mm}$, above the level of foramina of Monro, or grade $\mathrm{C}$ with asymmetrical lateral or multiple expansions). We therefore consider "giant" those adenomas with SSE of types C and $\mathrm{D}$, the critical threshold being a superior margin more than $20 \mathrm{~mm}$ above the jugum sphenoidale, regardless of the volume of the intrasellar tumor portion (Figure 1).

\section{Material and Methods}

During the twenty-five years from 1962 to October 1987, 77 patients with "giant" macroadenomas (SSE types C and D) have

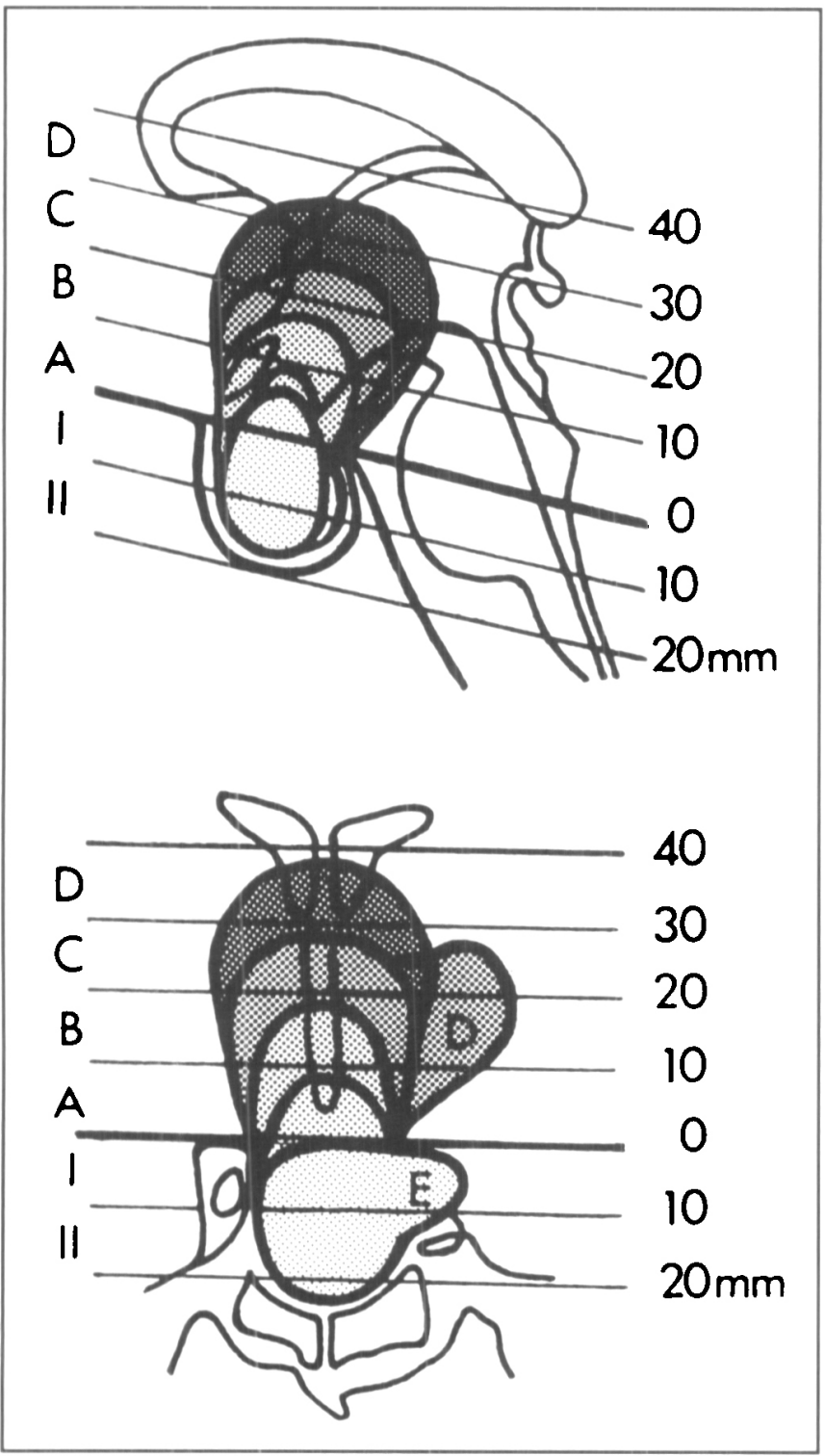

Figure I - Anatomic and radiologic classification of supra and parasellar extensions of pituitary adenomas. Giant adenomas include grades $C$ and $D$. starting from $20 \mathrm{~mm}$ above the level of the tuberculum sellae. been treated surgically at Notre-Dame Hospital, comprising $9.6 \%$ of the 800 pituitary adenomas treated by one of us (J.H.) over the same period of time in this hospital, the total series includes 400 additional cases operated on at the Montreal General Hospital (Table 1).

\section{Pathologic classification}

Non-secreting adenomas were present in 53 cases $(69 \%$ of 77): these represented $31 \%$ of the 168 non-secreting adenomas treated. Patients were males in 29 cases (mean age 47.8 years) and females in 24 cases (mean age 53.8 years).

Secreting adenomas were present in 24 cases (31\% of 77) with 16 males (mean age 40.3 years) and 8 females (mean age 28.2 years), accounting for only $3.8 \%$ of the total of 632 secreting adenomas treated during the same time-lapse. These 24 adenomas included 13 prolactinomas, 7 human growth hormone (HGH) adenomas, 2 gonadotrophinic adenomas, 1 adenocorticotropic adenoma and 1 thyreotropic adenoma.

\section{Radiologic classification}

With respect to the bony structures, the sella turcica was mildly enlarged and asymmetrical (grade I) in only 1 case, significantly enlarged, including local destruction of the sellar floor (grades II and III) in 62 cases $(80.5 \%$ ) and diffusely destroyed (grade IV, "phantom sella") in 14 cases ( $18.1 \%$ ). The suprasellar extensions were of type $\mathrm{C}$ (more than $20 \mathrm{~mm}$ above the jugum) in 66 cases $(85.7 \%), 49$ of which were non-secreting and 17 secreting adenomas, and SSE type D were found in 11 cases (14.3\% of 77 ) including 7 secreting and 4 non-secreting.

\section{Visual field disturbances}

Visual field defects were demonstrated preoperatively in 74 of 77 cases $(96 \%)$ and included complete bitemporal hemianopia in 41 cases $(53.2 \%)$, bilateral blindness in one patient with acute pituitary apoplexy, ${ }^{14}$ unilateral temporal hemianopia and contralateral blindness in 8 cases $(10 \%)$, unilateral quadranopia and contralateral hemianopia in 8 cases $(10 \%)$, unilateral hemianopia or quadranopia in 6 cases $(7.6 \%)$, bitemporal quadranopia in 8 cases $(10 \%)$. One patient with lateral temporal expansion showed a lateral homonymous hemianopia and 3 patients with presumably postfixed chiasm had normal visual fields.

\section{Endocrinologic disturbances}

The endocrinologic deficits were classified as major deficits (ACTH-insufficiency), or more minor deficits (FSH, LH, HGH or TSH insufficiency). Adequate endocrinologic preoperative data were available in 70 patients. Twenty-seven patients had major endocrine deficits (38.5\%), 20 of which had non-secreting and 7 secreting adenomas. Twenty-three patients (33\% from 70 ) had minor endocrine deficits, and 20 had no deficit at all $(28.5 \%)$.

Serum prolactin levels were available in 9 from 13 giant prolactinomas and ranged from $900 \mathrm{ng} / \mathrm{ml}$ to $30,900 \mathrm{ng} / \mathrm{ml}$, the mean PRL-level being $7,464 \mathrm{ng} / \mathrm{ml}$. The highest PRL-levels were found in invasive tumors of type D. 15,16,17,18,19

\section{Surgical Treatment and Operative Modalities}

The general surgical aspects of the transsphenoidal approach for large pituitary adenomas with suprasellar extension have been described in detail elsewhere. $20,21,22$ 
Table 2: Type of 99 Surgical Procedures Performed in 77 Patients with Giant Pituitary Adenomas

\begin{tabular}{l}
$\begin{array}{c}\text { SINGLE TRANSSPHENOIDAL PROCEDURE } \\
\text { (6 pat. previously op. elsewhere) } \\
\text { (T.S.: 3, T.C.: 3) }\end{array}$ \\
$\begin{array}{c}(57.5 \%) \\
\text { TWO T.S. (<2 MONTHS) } \\
\text { (two stages: 2, post-op. hemat.: 4) } \\
\text { (CSF-leak: 1, chiasmapexy: 1) }\end{array}$ \\
$\begin{array}{c}\text { TWO T.S. (LONG TERM) } \\
\text { (residual tumor or recurrence) }\end{array}$ \\
$\begin{array}{c}(8 \%) \\
\text { ONE OR TWO T.S. PLUS CRANIOTOMY }\end{array}$ \\
\hline
\end{tabular}

Ninety-nine surgical procedures have been carried out in these 77 patients with giant adenomas: 57 patients, 6 of which had previously undergone surgery elsewhere for the same condition, 3 transsphenoidally and 3 transcranially, had a single transsphenoidal procedure performed; 8 patients underwent two
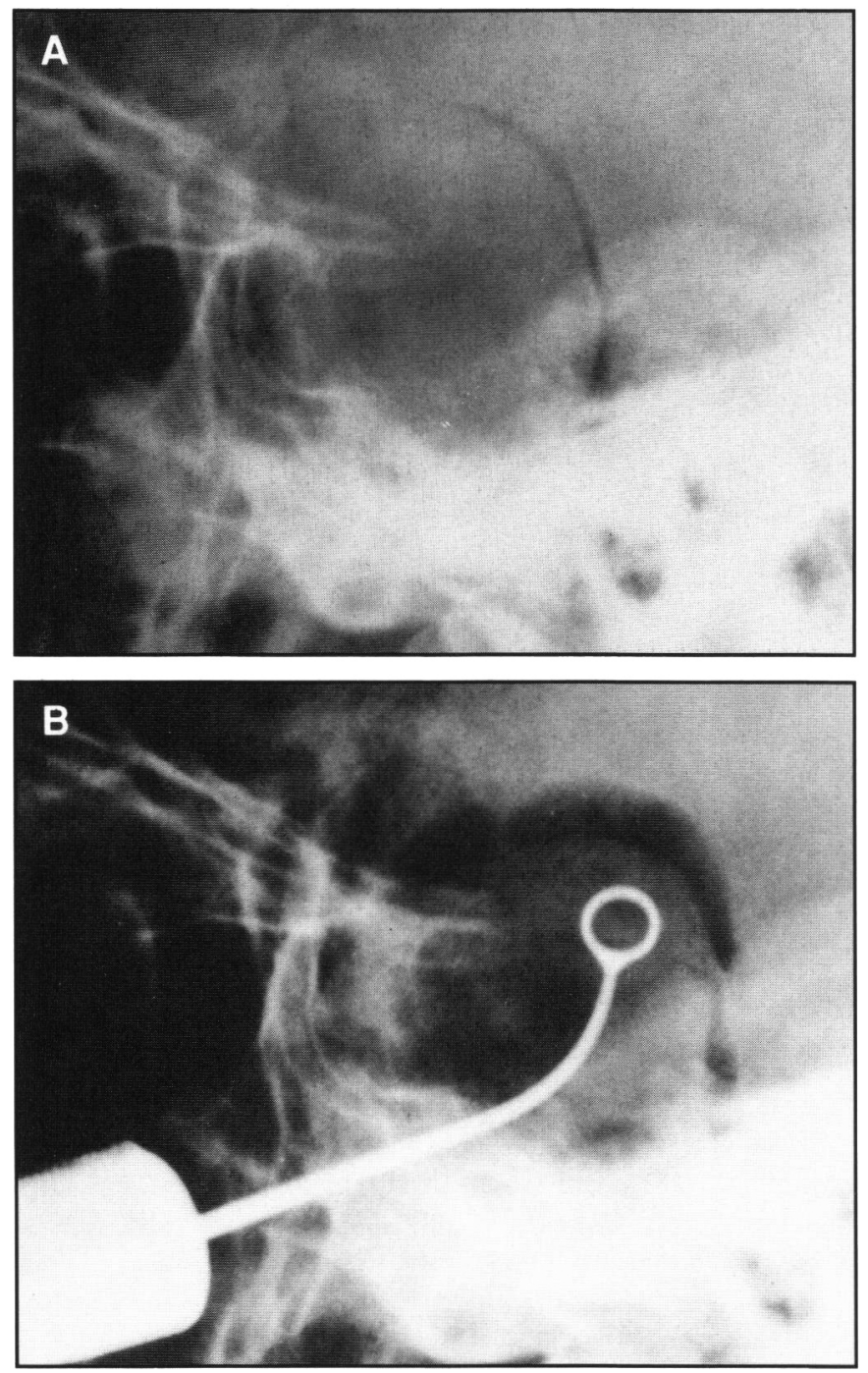

transsphenoidal procedures within 2 months from the first operation ( 2 cases for deliberate two-staged removal, 4 because of post-operative hematoma, 1 for post-operative CSF-leak, and 1 for chiasmapexy related to post-operative empty sella); two patients had two transsphenoidal procedures after prolonged intervals for residual or recurrent tumor; 3 patients had a transcranial approach after one or two transsphenoidal procedures (Table 2).

\section{Operative Technique for Large and Giant Pituitary Adenomas}

After exposure of the sellar floor using the conventional transrhinoseptal approach, the sella floor is widely opened to allow a maximal access to the lateral portions of the tumor. After removal of the intrasellar portion of the adenoma, which is usually relatively easy, attention is directed toward the suprasellar extension. Intra-operative pneumoencéphalograms using air administered via a lumbar catheter and in some instances before the era of CT-Scanning, immediate preoperative cisternographies were performed in 45 cases to obtain an outline of the
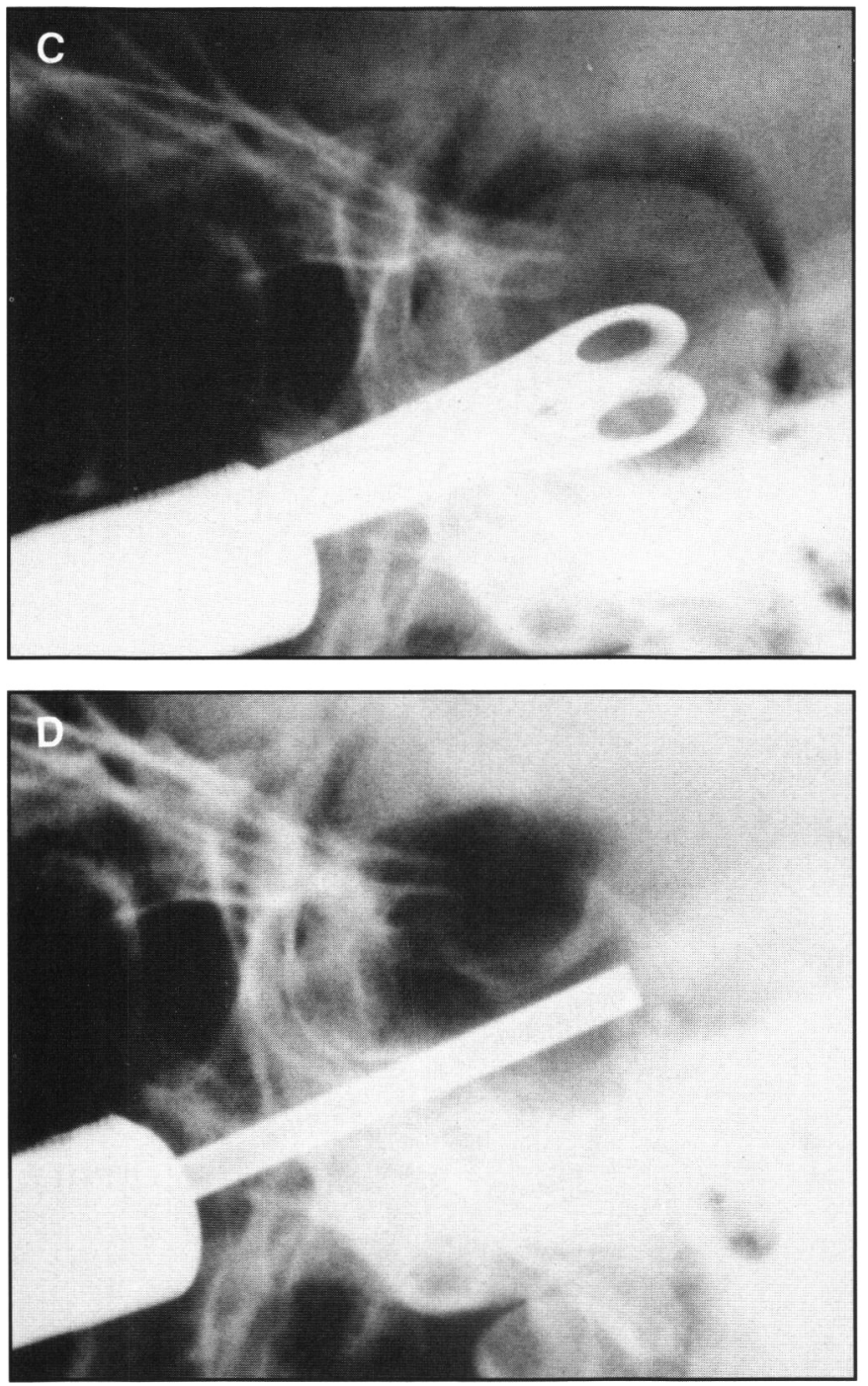

Figure 2 - A. Voluminous pituitary adenoma filling the sphenoid sinus and expanding upwards as outlined by air cisternography via lumbar injection (IIC). B. Partial debulking of tumor resulting in collapse of capsule as outlined by further air injection. C. Detachment of tumor fragments from underneath the diaphragm. D. Collapsed diaphragm outlined by air above in chiasmatic cistern and air below in the emptied sellar cavity. 
suprasellar extension and to follow the downward migration of the diaphragm on radiofluoroscopy (Figure 2). Angled curettes are used to scrape the residual suprasellar tumor remnants adherent to the diaphragm, and Valsalva-maneuvers are performed to help push the SSE down. Intratumoral contrast injections have been used in 3 instances, but this method has been abandoned since two patients demonstrated penetration of contrast into the intracranial subarachnoid space. Before the era of CT-Scanning metallic marker clips were applied in 21 cases on the diaphragma sellae to assess post-operatively the presence of early hematomas or later recurrent tumor growth. In 11 instances, intraoperative CSF-leak required extensive duroplasty using either fascia lata or more recently several layers of folded lyophilized homologous dura.

Significant amounts of recent liquefied blood were found in 9 tumors $(11.6 \%)$ and cystic degeneration with yellowish fluid were found in 11 cases $(14.2 \%)$.

The normal pituitary tissue was identified and preserved in 62 cases $(82 \%)$. The degree of tumor removal at first operation judged in 75 from 77 cases was: total selective removal in 49 cases $(65.3 \%)$, total non-selective (normal pituitary not identified) in 4 cases $(5.3 \%)$, subtotal selective in 13 cases $(17.3 \%)$ and subtotal non-selective in 9 cases $(12 \%)$.

\section{Operative complications}

From 99 procedures performed in 77 patients, the most significant complication was the development of postoperative hematomas which required operative decompression in 4 cases $(4.1 \%)$, all of whom died from related causes (one postoperative hematoma with ventricular hemorrhage in a 70-year-old patient with a large invasive prolactinoma, one postoperative hematoma after a second transsphenoidal procedure in a 25 -year-old patient with a prolactinoma who experienced cardiac arrest immediately after surgical decompression, one postoperative hematoma in a 72-year-old patient with a large invasive prolactinoma who developed bilateral carotid occlusions and cavernous sinus thrombosis, and one acute myocardial infarction 6 weeks after a postoperative hematoma and meningitis developed in a 52-year-old patient with a non-secreting adenoma). The overall procedure mortality is $4.1 \%$ of the 99 procedures and the management mortality is $5.2 \%$ ( 4 of 77 patients). One patient developed an empty sella syndrome with visual field deficit attributed to traction on the optic chiasm which required chiasmapexy: the transsphenoidal filling of the sella turcica with muscle and fascia lata resulted in reversal of symptoms. Two patients developed early postoperative Korsakoff's syndrome attributed to the compressive effect on the hypothalamus and possible intrasellar herniation of the diencephalon. Five patients required permanent therapy because of diabetes insipidus $(6.5 \%)$.

\section{Operative Results}

The overall results of the surgical management were estimated from 48 patients only, since adequate follow-up data were unavailable in 29 cases, mainly from overseas.

\section{Residual or recurrent tumor}

Altogether, 19 patients (39.5\%) were shown to have residual or recurrent tumor after the first operation on CT-scanning: of these, 12 underwent repeat surgery ( 9 transsphenoidally, and 3 transcranially after one or two repeat transsphenoidal procedures).

Radiotherapy was administered in 23 cases $(47.9 \%)$ after one or two operations.

Bromocriptine was administered postoperatively in 6 of 14 prolactin adenomas because of residual hyperprolactinemia.

\section{Postoperative endocrinologic deficits}

Sixty-one patients had adequate early postoperative biological endocrine data. A major deficit (ACTH or more) was present in 26 cases $(42.6 \%$ ), a minor deficit (TSH, HGH, LH, FSH but normal ACTH) was present in 15 cases $(24.6 \%)$ and no deficit was found in 20 cases $(32.7 \%)$; in total almost $60 \%$ of cases did not get major adrenocortical insufficiency.

\section{Postoperative visual function}

Sixty-three patients were evaluated postoperatively as to visual function ( 3 cases without visual symptoms pre-operatively and 11 cases without postoperative data): of these, 22 patients $(31.7 \%)$ showed total recovery and $36(57.1 \%)$ showed partial recovery. Five patients remained unchanged $(7.9 \%)$ and one patient $(1.5 \%)$ became completely blind.

\section{Discussion and Conclusions}

Based on the assessment of a large series of 77 giant adenomas (suprasellar extensions of more than $20 \mathrm{~mm}$ above the diaphragma sellae) we conclude that the transsphenoidal route is the preferred surgical approach. It allows an adequate removal of the tumor in most cases, either after one or two procedures. The deliberate two-staged removal has been shown to be particularly useful. Thus, transcranial procedures are rarely needed in our experience.23.24 We have not found any indication for simultaneous combined intra and extracranial approach ${ }^{31}$ which seems to be an excessively traumatic procedure with increased risk of infectious complications.

Complications of this transsphenoidal approach include postoperative hematomas which should be dealt with surgically very promptly to avoid hypothalamic damage: these hematomas account for the entire mortality in this series.

Efficient decompression of the optic structures can be obtained by the transsphenoidal approach and usually results in rapid improvement of visual acuity and visual fields. $26,27,28$

The recent introduction of the dopamine agonist bromocriptine in the preoperative management of large and giant secreting adenomas has shown that significant tumor reduction can be obtained, 29,30 but its long-term effect needs to be demonstrated.

The transsphenoidal route allows, even in giant tumors, the identification of the normal pituitary tissue in the majority of the cases, so that major pituitary insufficiency can be avoided in about $60 \%$ of the cases.

\section{ACKNOWLEDGEMENTS}

This work was supported by the Pituitary Research Foundation (Canada). It was presented on June 16th 1988 at the XXIIIrd Canadian Congress of Neurological Sciences, Quebec City. The manuscript was typed by Miss Hélène Lefrançois, scientific secretary.

\section{REFERENCES}

1. Jefferson G. Extrasellar extension of pituitary adenomas. Proc $R$ Soc Med 1940; 33: 433-458. 
2. Jefferson $G$. The invasive adenomas of the anterior pituitary. In: The Sherrington Lectures III. Liverpool: University Press of Liverpool 1955; 3-63.

3. Symon L, Jakubowski J, Kendall B. Surgical treatment of giant pituitary adenomas. J Neurol Neurosurg Psychiatry 1979; 42: 973-982.

4. Srivastava VK, Narayanawamy KS, Vasudevrao T. Giant pituitary adenomas. Surg Neurol 1983; 20: 379-382.

5. Hardy J. Trassphenoidal microsurgery of the normal and pathological pituitary. Clin Neurosurg 1969; 16: 185-217.

6. Symon L, Jakubowski J. Transcranial management of pituitary tumors with suprasellar extension. J Neurol Neurosurg Psychiatry 1979; 42: 123-133.

7. Fahlbusch R, Buchfelder M, Schrell U. Short-term preoperative treatment of macroprolactinomas by dopamine agonists. J Neurosurg 1987; 67: 807-815.

8. Bronsteim MD, Cardim, CS, Marino R. Short-term management of macroprolactinomas with a new injectable form of bromocriptine. Surg Neurol 1987; 28: 31-37.

9. Ciric, I, Mikhael M, Stafford T, et al. Transsphenoidal microsurgery of pituitary macroadenomas with long-term follow-up results. J Neurosurg 1983; 59: 395-401.

10. Nakane T, Kuwayama A, Watanabe M, et al. Transsphenoidal approach to pituitary adenomas with suprasellar extension. Surg Neurol 1981; 5: 225-229.

11. Guiot G. Adénomes hypophysaires, Masson, Paris 1958; 276 pp.

12. Aubourg PR, Derome PJ, Peillon F. Endocrine outcome after transsphenoidal adenomectomy for prolactinoma: prolactin levels and tumor size as predicting factors. Surg Neurol 1980; 14: 141-143.

13. Hardy J, Vezina JL. Transsphenoidal neurosurgery of intracranial neoplasms. In: Thompson RA, Green JR, eds. Advances in Neurology. New York: Raven Press 1976; 261-274.

14. Mohr G, Hardy J. Hemorrhage, necrosis and apoplexy in pituitary adenomas. Surg Neurol 1982; 18: 181-189.

15. Shucart WA. Implications of very high serum prolactin levels associated with pituitary tumors. J Neurosurg 1980; 52: 226-228.

16. King LW, Molitch ME, Gittinger JW, et al. Cavernous sinus syndrome due to prolactinoma: resolution with bromocriptine. Surg Neurol 1983; 19: 280-284.

17. Rilliet B, Mohr G, Robert F, et al. Calcifications in pituitary adenomas. Surg Neurol 1981; 15: 249-255.
18. Carapella CM, Pompei P, Mastrostefano R, et al. Calcified pituitary adenoma associated with severe hyperprolactinemia. J Neurosurg 1983; 59: 871-874.

19. Barrow DL, Mizuno J, Tindall GT. Management of prolactinomas associated with very high serum prolactin levels. J Neurosurg 1988; 68: 554-558.

20. Hardy J, Mohr G. Le prolactinome, aspects chirurgicaux. Neurochirurgie 1981; 27: 41-60 (Supp. 1).

21. Hardy J, Mohr G. The pituitary. In: Hardy JD, ed. Hardy's Textbook of Surgery (2nd ed.). Philadelphia: J.B. Lippincot Company 1988; 372-380.

22. Wilson CB. Neurosurgical management of large and invasive pituitary tumors. In: Tindall GT, Collins WF, eds. Clinical management of pituitary disorders. New York: Raven Press 1979; 335 342.

23. Ray BS, Patterson RH Jr. Surgical experience with chromophobe adenomas of the pituitary gland. J Neurosurg 1971; 34: 726-729.

24. Fager CA, Poppen JL, Takaoka Y. Indications for and results of surgical treatment of pituitary tumors by intracranial approach. In: Kohler PO, Ross GT, eds. Diagnosis and treatment of pituitary tumors. Amsterdam: Excerpta Medica 1973; 146-155.

25. Wilson CB, Dempsey LC. Transsphenoidal microsurgical removal of 250 pituitary adenomas. J Neurosurg 1978; 48: 13-22.

26. Melen $O$. Neuro-ophthalmologic features of pituitary tumors. $I n$. Pituitary Tumors: Diagnosis and Management. Endocrinology and Metabolism Clinics 1987; 16: 585-608.

27. Laws ER Jr, Trautmann JC, Hollenhorst RW Jr. Transsphenoidal decompression of the optic nerve and chiasm. J Neurosurg 1977 46: 717-722

28. Mohr G, Hardy J, Gauvin P. Chiasmal apoplexy due to ruptured cavernous hemangioma of the optic chiasm. Surg Neurol 1985; 24: $636-640$

29. Hubbard JL, Scheithauer BW, Aboud CF, et al. Prolactin-secreting adenomas: the preoperative response to bromocriptine treatment and surgical outcome. J Neurosurg 1987; 67: 816-821.

30. Van't Verlaat JW, Lancranjan I, Hendricks MJ, et al. Primary treatment of macroprolactinomas with Parlodel LAR. In: Van't Verlaat JW, ed. Secreting pituitary adenomas (Thesis, University of Utrecht, The Netherlands). Tripiti, Rotterdam 1988; 45-55.

31. Loyo M, Kleriga E, Mateos H, et al. Combined suprainfrasellar approach for large pituitary tumors. Neurosurgery $1984 ; 14: 485$ 488. 